\title{
A Miopia dA EFICIÊNCIA ENTREVISTA COM FÁbIO WANDERLEy ReIS
}

Fábio Wanderley Reis é professor emérito da Faculdade de Filosofia e Ciências Humanas da Universidade Federal de Minas Gerais. Doutor em Ciência Política pela Universidade Harvard, é organizador de trabalhos de relevo como $A$ democracia no Brasil: dilemas e perspectivas, com Guillermo 0'Donnell. Por seu Politica e Racionalidade, foi ganhador do Prêmio Anpocs, como melhor obra científica em Ciências Humanas. Seus livros mais recentes são Mercado e Utopia (Edusp, 2000) e Tempo Presente (Editora Ufmg, 2002). Obra labiríntica, por sua riqueza temática - uma visão panorâmica da política brasileira no último quarto de século -, Tempo Presente, resenhado por Mediações, revela-nos o alcance da atîvidade intelectual de um pensador dotado de vasta cultura política e de apurado grau de sofisticação analítica. Aposentado há alguns anos, depois de ensinar por mais de três décadas, ele tem participado ativamente do debate público. Os principais veículos de nossa grande imprensa têm dado destaque ao rigor crítico de suas idéias. Observador arguto da cena política brasileira atual, Fábio Wanderley concedeu a seguinte entrevista a Mediações.

Medraçס̃Es - Como o senbor avalia o contexto politico brasileiro neste periodo posterior às eleições municipais, tanto do ponto de vista geral, quanto do ponto de vista partidário?

FábIO WanderLeY ReIS - Avalio positivamente. As eleições corroboraram 0 que muita gente tem destacado, a polaridade que se vem estabelecendo há algum tempo entre PT e PSDB, em função especialmente do protagonismo dos dois partidos nas disputas presidenciais do período recente. Substituindo a turbulência do sistema partidário que temos tido desde a ditadura de 1964, o estabelecimento dessa polaridade me parece envolver a identificação mais estável dos eleitores com os dois partidos, 0 que pode vir a representar um obstáculo às lideranças populistas e clientelistas mais negativas, além de uma eventual simplificação "natural" e propícia do nosso sistema partidário. Por outro lado, ambos os partidos merecem ser vistos como progressistas, e a convergência do eleitorado em torno deles tende a representar um reforço do "centro", com pequenas oscilações à direita e à esquerda, que corrobora a inviabilidade eleitoral de extremismos de um 
tipo ou de outro.

MEDiaç⿸尸Es - Como o senhor analisa a posição do eleitor? Houve mudanças? Quais?

Fábio WanderLeY - A mudança que percebo é a que está expressa na resposta à pergunta anterior: com a estabilidade do quadro partidário e o protagonismo de dois partidos nas disputas eleitorais de maior importância, o eleitorado, que continua em grande medida alheio e desinformado com respeito à política, pode estabelecer identificações partidárias mais estáveis. Independentemente do conteúdo propriamente "ideológico" dessas identificações, que é sem dúvida precário, elas têm conseqüências positivas no sentido indicado.

Mediações - Depois de vários pleitos transcorridos dentro da normalidade é possivel falar em aumento da sofisticação do eleitor ou a sindrome do Flamengo continua a vigorar? Em que sentido? É possivel modificar essa situação? Como? Fábio Wanderley - 0 que eu andei chamando de "síndrome do Flamengo" não depende da normalidade ou anormalidade institucional do processo eleitoral, mas de fatores de ordem intelectual ou educacional ligados a aspectos mais estruturais e duradouros da vida brasileira. A síndrome seria conseqüência das deficiências existentes nesse plano. A alteração nas circunstâncias em que se dá o enfrentamento entre os partidos, com a polaridade PT-PSDB, pode ter conseqüências positivas mesmo na vigência continuada daquela síndrome e da precariedade "ideológica" que ela envolve. Mediaçós - 0 avanço do nivel educacional do eleitorado garantiria um aumento de sua sofisticação? Em que sentido ela poderia contribuir para o avanço da democracia?

Fábio Wanderley — 0 avanço efetivo quanto à educação certamente garantiria 0 aumento da sofisticação. A contribuição que isso traria para a democracia me parece bem clara, pois na medida desse aumento teríamos os eleitores tomando suas decisões de maneira mais informada e autônoma e prestando-se menos a manipulações de tipos diversos.

MediaçõEs - Em que medida "a dança das cadeiras" ou o troca-troca político partidário impacta no comportamento do eleitor?

Fábio WanderleY - Acho que o troca-troca tem a ver exatamente com a fluidez que vínhamos experimentando quanto ao quadro partidário e com a consequiência de que as identificações partidárias estáveis por parte do eleitor popular eram dificultadas. $\mathrm{Na}$ medida em que se produzam essas identificações (ou em que se criem identidades partidárias para o eleitor), 0 troca-troca ou a volubilidade partidária dos políticos tenderá a ser punida pelo eleitor no momento do voto. Lembre-se que, com todas as deficiências do eleitorado (que eram certamente maiores naquela época), não havia o troca-troca no período 1945-64: provavelmente como conseqüência da penetração popular da figura de Getúlio Vargas e do ponto de referência saliente que ele representava no enfrentamento dos partidos (PSD e PTB ligados a Vargas, UDN antivarguista), tornava-se impensável que os políticos saltitassem sem mais entre os partidos de importância.

Mediações - Como o eleitor brasileiro 
define seu voto?

FábIo Wanderley - Creio que a idéia da "síndrome do Flamengo", de que se falou antes, continua a ser relevante a respeito. Apesar de que haja, naturalmente, matizes diferentes nos estratos socioeconômicos e educacionais mais altos ou em certas "vanguardas" mesmo populares, o grosso do eleitorado popular continua a se orientar por polaridades singelas como as de "pobres" e "ricos" e a tomar posição em termos deficientes quanto à informação sobre questões específicas de qualquer natureza (institucionais, políticas, econômicas...).

MEDIAÇõEs - Qual sua posição em relação às discussões em torno da Reforma Política?

FábIO WANDERLEY - Minha posição é a de que, em geral, cabe tratar de ser flexível (mais flexível do que o Fla-Flu que costumamos encontrar nos debates correntes) diante da complexidade envolvida em vários dos temas relacionados com a reforma (majoritarismo versus proporcionalismo, parlamentarismo versus presidencialismo, estrutura partidária e sua reforma etc.). Creio que a principal dificuldade é a de como equilibrar adequadamente dois desideratos que se relacionam tensamente quanto a esses temas: 0 desiderato da representatividade democrática e o da eficiência tanto no plano da participação eleitoral quanto no que se refere à capacidade governativa. Há apenas dois itens com respeito aos quais me parece possível ter posições firmes: 0 do financiamento público das campanhas, que, com todas as dificuldades que haja para sua colocação adequada em prática, é indispensável para que se possa assegurar alguma igualdade no direito de ser votado (ao lado da igualdade no direito de votar); e o do voto facultativo ou obrigatório, onde me parece que a posição corrente de condenação do voto obrigatório envolve um grande equívoco. 0 voto facultativo está associado por toda parte com o fato de que são principalmente os setores populares e menos educados que deixam de votar; no caso brasileiro (onde mesmo com o voto obrigatório são esses setores os que menos votam), implantar o voto facultativo redundaria em criar um fator adicional de exclusão popular numa sociedade que já é excludente de muitas maneiras - e onde 0 momento do voto é o grande momento em que o povão se faz presente em decisões importantes.

MEDIAÇÕES - O senhor afirmou em várias situações que a eleição de um presidente petista era um teste importante para a democracia no Brasil e afirmou, também, que a essa possibilidade dependia da desideologização do partido. Hoje temos um presidente petista, um metalúrgico nordestino, e um discurso e uma prática bastante distantes da defesa do socialismo feita pelo partido nos seus primórdios. A mudança de posição do partido, ou sua desideologização continuam a fazer com que o teste para a democracia seja efetivo?

Fábio Wanderley - Não faria sentido pretender que o teste só seria real se o PT, no governo, continuasse empenhado em fazer "a revolução" ou algo parecido e ainda assim a democracia resistisse - ela certamente não resistiria. Isso faz lembrar a posição escalafobética que Roberto Mangabeira Unger defendia a respeito da 
Assembléia Constituinte de alguns anos atrás, que segundo ele deveria tratar de consagrar a "subversão permanente": ainda que se possa pretender que temos aí boa doutrina (instituições políticas boas são idealmente aquelas que se mostrem capazes de processar até as mudanças revolucionárias por meio de seus próprios formalismos institucionais), como sociologia política supostamente realista aplicada à sociedade brasileira atual trata-se sem dúvida de uma proposta insustentável. Lembre-se que na trajetória dos partidos social-democráticos da Europa, por exemplo, o que se teve foi também o aprendizado de realismo e moderação eleitoral e administrativa. Da mesma forma, o que cabe esperar aqui é que a esquerda, que sempre foi objeto de suspeita do establishment, ao chegar ao poder passe pelo mesmo aprendizado, possibilitando 0 desarmamento dos espíritos também do outro lado e a eventual consolidação institucional da democracia. 0 grande desafio é fazer isso mantendo a sensibilidade social e o empenho com os compromissos que daí decorrem, mesmo se tais compromissos têm necessariamente de ser vistos numa perspectiva de avanço gradual e de mais longo prazo.

MEDIAÇбES - Em que sentido a trajetória do PT diverge da trajetória da socialdemocracia européia?

FÁBIO WANDERLEY - Acho que difere por pelo menos dois aspectos bem claros. Em primeiro lugar, as precariedades do substrato popular e eleitoral com que o partido pode contar, devido ao peso do nosso legado escravista, ao fosso social resultante e às carências do eleitorado popular de que se falou antes. Em segundo lugar, as circunstâncias trazidas pela globalização e sua dinâmica, que criam obstáculos dramáticos para a social-democracia até no caso dos países em que ela tem longa tradição. Assim, os desafios, no nosso caso, são muito mais difíceis e complicados.

MEdiaçõ - Podemos dizer que a política econômica do governo Lula tem obtido sucesso no sentido de garantir a adequação ao mercado globalizado, o que permitiu que fossem superados os riscos da rejeição do mercado ao governo e o risco de uma crise institucional. A superação desses riscos poderia garantir a retomada de um projeto de compromisso social. Como articular boa política econômica, nos termos em que isso é compreendido boje, e execução de politicas sociais?

Fábio WanderLeY - Esse é o aspecto crucial dos desafios difíceis de que falei na resposta anterior. Naturalmente, há urgências que têm de ser atendidas por meio de medidas de assistencialismo paternalista (tipo Fome Zero ou o que mais seja, com toda a eficiência possível...). Mas, se não quisermos ficar nesse paternalismo, é claro que a política social tem de estar acoplada a boa política econômica (isto é, política econômica atenta para as constrições e limitações do ambiente real em que se executa) que possa resultar na incorporação econômico-social mais efetiva e consistente da população carente ou marginal e que reduza a pobreza e a desigualdade. A verdade é que ninguém sabe mesmo como atender a essa complicação de maneira efetiva. Tanto mais que a complicação pode ser vista como maior ainda quando se atenta para o fato de que 
os próprios economistas costumam distinguir uma eficiência imediatista ou míope de outra que supõe condições sociais gerais propícias a melhor desempenho econômico ou maior produtividade - ou seja, supõe justamente que a política social tenha sido executada com êxito. É claro, em certas circunstâncias, como as da eleição e do início do governo Lula, trata-se de apagar incêndio e não há como fugir da busca "míope" de eficiência. Mas, quanto ao resto, é difícil escapar de recomendações banais que acabam redundando em dizer que é preciso fazer tudo.

MEDIAÇOES - O senbor tem afirmado que ainda não demos solução satisfatória ao nosso "problema constitucional". Como poderíamos fazer isso?

Fábio WanderLeY — Pois é... Teremos feito isso no momento em que tivermos desatado o nó indicado na resposta anterior.

MEDLAÇ̃̃ES - Qual a sua posição em relação às politicas afirmativas, especialmente em relação à discussão de cotas?

Fábio WANDERLEY - Sou inequivocamente favorável à ação afirmativa num sentido geral, além de me identificar, naturalmente, com os que denunciam os dramas e ruindades que ocorrem especificamente no plano das relações raciais no país. Mas isso não me leva a apoiar a política de cotas estabelecidas em termos raciais, ou a concordar com muitas análises equivocadas de gente ligada, por exemplo, ao movimento negro no Brasil. Além do problema "técnico" de estabelecer quem é e quem não é negro no Brasil, há o problema humano do que haveria de odioso em classificar racialmente a população carente para habilitá-la aos benefícios das políticas. Creio que o critério de ação (mesmo do recurso a cotas) tem de ser um critério social, e acho que o exemplo a ser seguido a respeito é o de Cuba, que os estudos mostram ter tido êxito singular em promover a população negra sem jamais ter tido políticas estabelecidas em termos especificamente raciais.

Mediaçõ - Durante bastante tempo o senhor foi visto por grupos de esquerda, especialmente petistas, como conservador, como liberal, como alguém que estava em trincheiras opostas a esses grupos. Nos últimos anos o senbor tem saído em defesa da opção petista. Quem mudou e quais foram as mudanças? Quais as suas opiniões atuais sobre o PT e sobre o governo Lula?

FÁbIO WandERLEY - Eu certamente não mudei quanto a minhas proposições fundamentais, que envolviam justamente a idéia de que o PT tinha de mudar se quisesse viabilizar-se (posso evocar, por exemplo, um artigo no Jornal do Brasil a propósito das eleições de 1982, agora republicado no meu livro Tempo Presente, em que eu já sustentava isso). Creio que o PT, que me parece representar um experimento singular e positivo em nossa história políticopartidária, de fato mudou e vem mudando, e acho bom para o país que isso aconteça.

Entrevista concedida a CRISTiane de CASTRo e ALmeida em novembro de 2004. 